\title{
Can we reduce CT scan and hospital costs in children with blunt trauma using four parameters?
}

Tülin Öztaş ${ }^{1^{*}} \mathbb{D}$, Songül Araç ${ }^{2}$ and Salim Bilici ${ }^{1}$

\begin{abstract}
Background: Blunt trauma is one of the most common causes of admission to the emergency service in childhood. Children with trauma are generally evaluated in emergency services where pediatric and adult patients are together, and difficulties are experienced in managing children exposed to trauma. CT is preferred for quick detection and grading of toracoabdominal, skeleton, and neurological injury in high energy trauma. The present study aims to determine the severity of trauma and whether $\mathrm{CT}$ exposure can be reduced and patient cost using four parameters.

This study was conducted with 586 pediatric patients exposed to blunt abdominal trauma. The clinical prediction rule consisted of four parameters, including abdominal pain, physical examination findings, aspartate aminotransferase (AST), and chest $x$-ray (CXR, which was used to predict intraabdominal injury in patients with blunt trauma. Patients with no parameters of the clinical decision rule were considered very low risk, and those with one or more parameters were considered at risk. The hospital cost of the patients with and without clinical decision rule was calculated and compared.
\end{abstract}

Results: In our study, according to the four-variable clinical prediction rule, $88.1 \%$ of the patients had a very low risk of intraabdominal injury and $11.9 \%$ of them were at risk. The sensitivity was $97.3 \%$, specificity $98.2 \%$, and accuracy was $97.4 \%$ in very low-risk patients with four variables clinical prediction rule. In the very low-risk patients, the abnormal $\mathrm{CT}$ rate was $0.3 \%$ and conservative treatment was performed. With the use of four variables, $0.17 \%$ of solid organ injuries may be overlooked. In the risk of patients, $2.9 \%$ of these patients were abnormal CT findings, while tube thoracostomy was performed in four patients with pneumothorax, conservative treatment was performed in other patients. It was determined that routine computed tomography scan increased the patient cost by 5.5 times.

Conclusion: Patients exposed to blunt trauma with a very low risk of intra-abdominal injury can be identified with a four-variable clinical prediction rule. According to the four-variable clinical prediction rule, very low-risk patients do not require immediate $\mathrm{CT}$. The hospital costs can be reduced by reducing the $\mathrm{CT}$ scan. However, it should be kept in mind that a small proportion of intra-abdominal injuries may be overlooked.

Keywords: Blunt abdominal trauma, Clinical decision rule, Childhood blunt trauma, Cost analysis

\footnotetext{
${ }^{*}$ Correspondence: tulinoztas@hotmail.com

${ }^{1}$ Department of Pediatric Surgery, University of Health Sciences

Diyarbakır Gazi Yaşargil Training and Research Hospital, Diyarbakır, Turkey

Full list of author information is available at the end of the article
}

\section{Background}

Blunt trauma is one of the most common causes of admission to the emergency service in childhood. Children with trauma are generally evaluated in emergency services where pediatric and adult patients are together, and difficulties are experienced in the management of children exposed to trauma. While examining other 
systems such as the head and thorax in patients with blunt trauma, abdominal computed tomography $(\mathrm{CT})$ is usually performed in emergency services not to miss possible intra-abdominal injury [1]. Although CT is one of the best imaging methods for evaluating intra-abdominal injury after trauma, it has disadvantages such as exposure to radiation, difficulty in transportation, and high hospital costs [2]. When making a CT scan decision, it should be considered that the risk of cancer development in children due to radiation is higher than in adults [1, 3-8]. Approximately $90 \%$ of patients with blunt trauma are treated nonoperatively and CT does not affect the treatment method in most patients [9]. Therefore, it has been suggested that $\mathrm{CT}$ should be preferred in patients with high intra-abdominal injury risk $[1,6,7]$. With the history, physical examination, complete blood count, urinalysis, and laboratory tests such as hepatic transaminases, pancreatic enzymes, conventional radiographs, and Focused Assessment with Sonography for Trauma (FAST) results are an idea about the severity of intraabdominal injury and trauma can be obtained [1, 8-14]. This study aims to determine the severity of trauma in children using four parameters. The second aim is to investigate whether $\mathrm{CT}$ exposure can be reduced by applying the prediction rule. The final aim is to assess patient cost using four parameters.

\section{Methods}

Data of 586 patients who were exposed to blunt abdominal trauma between the ages of 18 months and 17 years, who were admitted to the emergency department of our hospital between April 2019 and October 2020, were retrospectively analyzed in this study. Patients with isolated head, extremity, or genital trauma, patients who were admitted $6 \mathrm{~h}$ after the trauma, those who underwent a CT scan in another center, who underwent peritoneal lavage, and who had incomplete data were excluded from this study. The present study was approved by the Institutional Ethics Committee.

In our study, intra-abdominal injury in patients with blunt trauma was tried to be predicted using the clinical prediction rule that includes four parameters: (1) abdominal pain, (2) abnormal physical examination finding (abdominal wall trauma sign, distension, tenderness, rebound tenderness), (3) AST > 200 IU/L, and (4) abnormal CXR (contusion, pneumothorax, hemothorax, rib fracture). According to the results of clinical prediction rule, patients were divided into two groups as very low risk and risk for intra-abdominal injury. Patients with no parameters of the clinical decision rule were considered very low risk, and those with one or more parameters were considered at risk. The necessity of urgent CT imaging in very low-risk patients according to clinical decision rules was questioned.

Age, gender, trauma mechanism, hospital admission period after trauma, abdominal pain, physical examination findings, hemogram and biochemistry values, conventional radiography, FAST, and CT reports were recorded on the patient evaluation forms prepared for the present study. The treatments were applied, and duration of hospital stay and results were evaluated. Abdomen CT findings were evaluated in five categories as contusion in solid organs, hematoma, laceration, intraperitoneal fluid, and intraperitoneal free air. FAST reports were evaluated as contusion, hematoma, and intraperitoneal fluid in solid organs. The management of the patients was grouped as observation in the emergency service, pediatric surgery service, or admission to the intensive care unit. The hospital cost of the patients with and without clinical decision rule was calculated and compared.

Seven days following the discharge, the families of the patients were contacted by telephone [6]. For patients who cannot be reached by phone, medical records were reviewed during the same follow-up period. The results of the clinical rule for measuring sensitivity, specificity accuracy, negative predictive values (NPV), and positive predictive values (PPV) were compared to a determined 7 days follow-up period without deterioration of traumatized patients after discharge.

\section{Statistical methods}

The data obtained from this research were statistically analyzed using SPSS (SocialSciences software package version 22.0 Windows) software program. Categorical variables were specified as number $(n)$ and percentage (\%). Numerical variables with normal distribution were shown as mean \pm standard deviation. Multiple regression analysis was performed to assess the prediction of intraabdominal injury of a clinical prediction rule. $P<0.05$ was considered statistically significant. The sensitivity, specificity, positive and negative prediction, negative probability, and accuracy of the four-variable clinical prediction rule were calculated in patients with and without intra-abdominal injury.

\section{Results}

Of the 586 patients included in this study, 376 were males, 210 were females, and the mean age was $10.1 \pm 5.7$ years (18 months -17 years). In this study, $90.9 \%$ of the patients were brought to the hospital $1 \mathrm{~h}$ after the trauma and 9.1\% 2 to $5 \mathrm{~h}$ after the trauma. The abnormal CT rate was $3.2 \%$, and the abnormal rate FAST was $4.4 \%$ of patients participating in the study. Higher positive FAST percentage but percentage of solid organ injury $(0.5 \%)$ was lower than CT (2.5\%). 
In our study, $88.1 \%$ (516) of the patients were at very low risk according to the four-variable clinical prediction rule. In very low-risk patients for intraabdominal injury, the abnormal CT rate was $0.3 \%$ (spleen contusion $n=1$ ). With the use of four variables, $0.17 \%$ of solid organ injury may be overlooked. $97.1 \%$ of the patients were observed in the emergency service, $2.9 \%$ were hospitalized in the pediatric surgery service, and conservative treatment was performed.

In this study, $11.9 \%$ (70) of the patients were considered at risk for intra-abdominal injury. $2.9 \%$ of these patients were abnormal CT findings. $54.2 \%$ of the patients were admitted to the emergency service observation, $14.2 \%$ to intensive care, and $31 \%$ to pediatric surgery. While tube thoracostomy was performed in four patients with pneumothorax, conservative treatment was performed in other patients. The mean duration of stay in the intensive care unit was $1.4 \pm 0.5$ days (1-2 days), and the average length of stay in the ward was $4.6 \pm 1.1$ days ( $3-7$ days) (Table 1).

The sensitivity was $97.3 \%$, specificity was $98.2 \%$, and accuracy was $97.4 \%$ in very low-risk patients with four variables of clinical prediction rule. In patients with intra-abdominal injury, the sensitivity was $90.3 \%$, specificity $93.7 \%$, and accuracy was $90.2 \%$ (Table 2 ).

The cost of each patient who was considered to be at very low risk for intra-abdominal injury and underwent a CT scan was $291.5 \mathrm{TL}$, and the cost of a patient considered to be very low risk and without CT was 53 TL. It was determined that routine $\mathrm{CT}$ scan increased the patient's cost 5.5 times (Table 3).

\section{Discussion}

Many factors from delayed diagnosis to morbidity, mortality, malpractice anxiety, and hospital cost play a role in the management of patients with blunt trauma. CT is preferred for quick detection and grading of toracoabdominal, skeleton, and neurological injury in highenergy trauma [15]. However, it is difficult to distinguish between which patients $\mathrm{CT}$ is necessary and between which it is unnecessary. No pathological finding is observed in $74 \%$ of CTs performed in patients with blunt trauma [5]. In the study of Streck et al., it was reported that approximately $15 \%$ of patients with blunt trauma had intra-abdominal injuries and that non-operative treatment was generally sufficient [1]. In our study, $83.8 \%$ of

Table 1 According to risk groups, the demographic, and radiological data of the patients

\begin{tabular}{|c|c|c|c|}
\hline & $\begin{array}{l}\text { Patients with very low risk } \\
n=516 \\
n(\%)\end{array}$ & $\begin{array}{l}\text { Patients with risk } \\
n=70 \\
n(\%)\end{array}$ & $\begin{array}{l}\text { Total } \\
586 \\
n(\%)\end{array}$ \\
\hline Mean age (years) & $10.1 \pm 4.7$ & $10.1 \pm 4.5$ & $10.2 \pm 3.7$ \\
\hline \multicolumn{4}{|l|}{ Gender } \\
\hline Female & $191(37.1)$ & $19(27.1)$ & $210(35.8)$ \\
\hline Male & $325(62.9)$ & $51(72.9)$ & $376(64.2)$ \\
\hline \multicolumn{4}{|l|}{ Trauma mechanism } \\
\hline Falling from height & $351(68.1)$ & $45(64.3)$ & $396(67.5)$ \\
\hline Motor vehicle accident & $122(23.6)$ & $14(20)$ & $136(23.2)$ \\
\hline Falling objects & $27(5.2)$ & $6(8.5)$ & $33(5.6)$ \\
\hline Motor vehicle crash & $16(3.1)$ & $5(7.1)$ & $21(3.6)$ \\
\hline \multicolumn{4}{|l|}{ CXR } \\
\hline Pneumothorax & & $2(2.8)$ & $2(0.3)$ \\
\hline Pneumothorax+clavicula fracture & & $3(4.3)$ & $3(0.5)$ \\
\hline Lung contusion & & $2(2.8)$ & $2(0.3)$ \\
\hline \multicolumn{4}{|l|}{ Abdominal CT } \\
\hline Spleen & $1(0.2)$ & $6(8.6)$ & $7(1.2)$ \\
\hline Liver & & $4(5.7)$ & $4(0.7)$ \\
\hline Kidney & & $4(5.7)$ & $4(0.7)$ \\
\hline Intraabdominal free fluid & $1(0.2)$ & $3(4.2)$ & $4(0.7)$ \\
\hline \multicolumn{4}{|l|}{ FAST } \\
\hline Kidney & & $2(2.8)$ & $2(0.3)$ \\
\hline Spleen & & $1(1.4)$ & $1(0.2)$ \\
\hline Intraabdominal free fluid & $10(1.9)$ & $10(14.2)$ & $20(3.4)$ \\
\hline
\end{tabular}

CXR chest $\mathrm{x}$-ray, CT computed tomography, FAST focused assessment with sonography for trauma 
Table 2 Performance of clinical decision rule

\begin{tabular}{lll}
\hline & Patients without IAI (95\%Cl) & Patients with IAI (95\%Cl) \\
\hline Sensitivity & $97.3 \%(95.6-98.5)$ & $93.3 \%(68.1-99.8)$ \\
Specificity & $98.2 \%(90.6-99.89)$ & $90.1 \%(87.4-92.5)$ \\
Positive predictive value & $99.8(98.6-99.9)$ & $20(15.8-24.9)$ \\
Negative predictive value & $80(70.4-87.1)$ & $99.8(98.7-99.9)$ \\
Negative likelihood ratio & $0.03(0.02-0.05)$ & $0.07(0.01-0.4)$ \\
Accuracy & $97.4(95.8-98.5)$ & $90.2(87.5-92.5)$ \\
\hline
\end{tabular}

IAI intraabdominal injury

Table 3 The hospital cost of each patients

\begin{tabular}{|c|c|}
\hline Outcome & Total cost (TL) \\
\hline Patient with IAI, abnormal CT, and admitted to hospital & 563.48 \\
\hline $\begin{array}{l}\text { Patient with } \mid \mathrm{Al} \text {, abnormal } \mathrm{CT} \text {, and observation in the } \\
\text { emergency service }\end{array}$ & 366.16 \\
\hline Patient without IAI, normal CT, and discharge & 291.51 \\
\hline Patient without $\mid \mathrm{Al}$, not receiving $\mathrm{CT}$, and discharge & 53 \\
\hline
\end{tabular}

$I A /$ intraabdominal injury, $C T$ computed tomography

abdominal CT performed with suspicion of intra-abdominal injury were normal. In our study, $2.5 \%$ intra-abdominal injury was detected. It was thought that the reason for the low rate of intra-abdominal injury in our study might be related to the fact that this study was performed in the general emergency service, not in the trauma center, unlike other studies.

In the study conducted by Streck et al., a clinical prediction rule containing five variables (abdominal pain, abnormal physical examination findings, abnormal CXR, AST $>200 \mathrm{IU} / \mathrm{L}$, and amylase) was defined and it was emphasized that the application of this clinical prediction rule could help the emergency physician to make a CT scan decision in the evaluation of blunt trauma patients [8]. It has been reported that the intra-abdominal injury risk of the patients was determined in a short time and that $\mathrm{CT}$ was not required in the first evaluation in one third of the patients [8]. In another study, it was observed that the sensitivity of the five-variable clinical prediction rule in determining the risk of intra-abdominal injury was $97.5 \%$ and intra-abdominal injury was missed by $0.7 \%$ [10]. With the application of clinical prediction rule consisting of history and physical examination, $0.5 \%$ intra-abdominal injury was missed, CT scan decreased $23.2 \%$, and hospital cost was reduced by $50 \%$ [6]. In the emergency department of our hospital, if the quaternary variable consisting of abdominal pain, abnormal physical examination finding, CXR, and AST $>200 \mathrm{IU} / \mathrm{L}$ is applied, the intra-abdominal injury may not be detected in only $0.17 \%$ of children with blunt trauma. The results of our study showed that the four-variable clinical prediction rule had a higher sensitivity and accuracy rate in identifying patients with a very low risk of intra-abdominal injury than patients with intra-abdominal organ injury. According to the four-variable clinical prediction rule, very low-risk patients do not require immediate $\mathrm{CT}$. In very low-risk patients, we recommend $12-24 \mathrm{~h}$ of observation to avoid missing injuries. If we had applied the clinical prediction rule when evaluating patients, the number of CT scan would have been reduced by $50.5 \%$ and the hospital cost would have been reduced by $23.6 \%$. The findings obtained in this study suggest that the application of the four-variable clinical prediction rule could reduce CT imaging and prevent unnecessary radiation exposure of the patients.

History and physical examination have an important role in the management of patients with blunt trauma $[1,7,16,17]$. Holmes et al. reported that $0.1 \%$ of blunt trauma patients were abducted, CT scan was reported to decrease $23 \%$ by clinical decision rule including abdominal wall trauma symptom, Glasgow Coma Scale (GKS) score $>13$, abdominal tenderness, thoracic wall trauma, abdominal pain, decreased respiratory noise, and vomiting [6]. Patients with abdominal pain, signs of peritoneal irritation, and abdominal wall trauma have a high risk of intra-abdominal injury [6,9]. In our study, abdominal pain, abdominal guarding, and signs of trauma in the abdominal wall were associated with intra-abdominal organ injury, and it supported no need for urgent CT scans in patients without these findings.

Clinical prediction rules including laboratory tests such as pancreatic enzymes and hepatic transaminases have been used to detect intra-abdominal injury in patients with blunt trauma $[9,11,16]$. It was thought that increased AST increased the sensitivity of the clinical prediction rule [14], and an AST $>200 \mathrm{IU} / \mathrm{L}$ could be an indication for a CT scan [18]. In the study of Streck et al., it was stated that AST reflects potential liver damage or ischemia, which was high in $68.8 \%$ of patients with intra-abdominal injury [1]. In patients with blunt trauma, the elevation of AST or ALT alone does not diagnose liver injury. AST, ALT, examination, and hemodynamic status should be evaluated together [18]. In our 
study, $40 \%$ of patients with intra-abdominal injuries had AST $>200 \mathrm{IU} / \mathrm{L}$. The results of our study suggest that patients with $\mathrm{AST} \leq 200 \mathrm{U} / \mathrm{L}$ can be evaluated together with history and examination instead of emergency CT.

Routine CXR in patients with trauma is significant for parenchymal evaluation and detecting rib fractures that may occur in proportion to the severity of trauma [19]. It has been recommended that patients with rib fractures should be evaluated with further examination [20]. Patients with pathology on CXR have low GCS, and CT indication cannot be made only with low GCS [21]. Our study supports that although pneumothorax, lung contusion, and rib fracture, if other examination and laboratory findings are normal, immediate abdominal CT is not required, and close follow-up is required.

\section{Limitations}

The limitations of our study are as follows: a singlecenter, retrospective, general emergency service where pediatric and adult patients were evaluated together. There is a need for prospective and multi-center studies to be conducted in a pediatric trauma center.

\section{Conclusions}

Patients with very low intra-abdominal injury risk exposed to blunt trauma can be identified with a fourvariable clinical prediction rule. According to the fourvariable clinical prediction rule, very low-risk patients do not require immediate CT. The hospital costs can be reduced by reducing the $\mathrm{CT}$ scan. However, it should be kept in mind that a low rate of intra-abdominal injuries may be overlooked by applying a four-variable clinical prediction rule.

\section{Abbreviations}

CT: Computed tomography; FAST: Focused Assessment with Sonography for Trauma; AST: Aspartate aminotransferase; CXR: Chest X-ray; GKS: Glasgow Coma Scale; NPV: Negative predictive values; PPV: Positive predictive values.

\section{Acknowledgements}

Not applicable.

\section{Authors' contributions}

T.Ö., S.A., and SB contributed to the literature search and the study design; T.Ö., S.A., and SB contributed to the data collection, statistical data analysıs, and data interpretation and the drafting manuscript and approved the final version. The authors have read and approved the manuscript.

\section{Funding}

The author(s) received no financial support for the research, authorship, and/ or publication of this article.

\section{Availability of data and materials}

The datasets (SPSS files) used and/or analyzed during the current study are available from the corresponding author on reasonable request.

\section{Declarations}

\section{Ethics approval and consent to participate}

The study was approved by the Clinical Studies Ethics Committee of Health Sciences University (08.03.2019/number: 238). Since the study was of a retrospective nature, informed consent was not obtained from the participants. However, written informed consent was obtained from the parents of the patients for the examinations and treatments to be performed upon arrival at the hospital.

\section{Consent for publication}

Not applicable.

\section{Competing interests}

The authors declare that they have no competing interests.

\section{Author details}

'Department of Pediatric Surgery, University of Health Sciences Diyarbakır Gazi Yaşargil Training and Research Hospital, Diyarbakır, Turkey. ${ }^{2}$ Department of Emergency, University of Health Sciences Diyarbakır Gazi Yaşargil Training and Research Hospital, Diyarbakır, Turkey.

Received: 3 July 2021 Accepted: 22 October 2021

Published online: 01 February 2022

\section{References}

1. Streck CJ Jr, Jewett BM, Wahlquist AH, Gutierrez PS, Russell WS. Evaluation for intra-abdominal injury in children after blunt torso trauma: can we reduce unnecessary abdominal computed tomography by utilizing a clinical prediction model? J Trauma Acute Care Surg. 2012;73:371-6.

2. Cook SH, Fielding JR, Phillips JD. Repeat abdominal computed tomography scans after pediatric blunt abdominal trauma: missed injuries, extra costs, and unnecessary radiation exposure. J Pediatr Surg. 2010;45:2019-24

3. Nishijima DK, Yang Z, Clark JA, Kuppermann N, Holmes JF, Melnikow J. A cost-effectiveness analysis comparing a clinical decision rule versus usual care to risk stratify children for intraabdominal injury after blunt torso trauma. Acad Emerg Med. 2013;20:1131-8.

4. Mahajan P, Kuppermann N, Tunik M, Yen K, Atabaki SM, Lee LK, et al. Comparison of clinician suspicion versus a clinical prediction rule in identifying children at risk for intra-abdominal injuries after blunt torso trauma. Acad Emerg Med. 2015;22:1034-41.

5. Hershkovitz Y, Zoarets I, Stepansky A, Kozer E, Shapira Z, Klin B, et al. Computed tomography is not justified in every pediatric blunt trauma patient with a suspicious mechanism of injury. Am J Emerg Med. 2014;32:697-9.

6. Holmes JF, Lillis K, Monroe D, Borgialli D, Kerrey BT, Mahajan P, et al. Identifying children at very low risk of clinically important blunt abdominal injuries. Ann Emerg Med. 2013;62:107-16.e2.

7. Springer E, Frazier SB, Arnold DH, Vukovic AA. External validation of a clinical prediction rule for very low risk pediatric blunt abdominal trauma. Am J Emerg Med. 2019;37:1643-8.

8. Streck CJ, Vogel AM, Zhang J, Huang EY, Santore MT, Tsao K, et al. Identifying children at very low risk for blunt intra-abdominal injury in whom CT of the abdomen can be avoided safely. J Am Coll Surg. 2017;224:449-58. e3.

9. de Jong WJ, Stoepker L, Nellensteijn DR, Groen H, El Moumni M, Hulscher JB. External validation of the blunt abdominal trauma in children (BATiC) score: ruling out significant abdominal injury in children. J Trauma and Acute Care Surg. 2014;76:1282-7.

10. Arbra CA, Vogel AM, Plumblee L, Zhang J, Mauldin PD, Dassinger MS, et al. External validation of a five-variable clinical prediction rule for identifying children at very low risk for intra-abdominal injury after blunt abdominal trauma. J Trauma Acute Care Surg. 2018:85:71-7.

11. Acker SN, Stewart CL, Roosevelt GE, Partrick DA, Moore EE, Bensard DD. When is it safe to forgo abdominal $\mathrm{CT}$ in blunt-injured children? Surgery. 2015;158:408-12. 
12. Karam O, Sanchez O, Chardot C, La Scala G. Blunt abdominal trauma in children: a score to predict the absence of organ injury. J Pediatr. 2009;154:912-7.

13. Leeper CM, Nasr I, Koff A, McKenna C, Gaines BA. Implementation of clinical effectiveness guidelines for solid organ injury after trauma: 10-year experience at a level 1 pediatric trauma center. J Pediatr Surg. 2018;53:775-9.

14. Hynick NH, Brennan M, Schmit P, Noseworthy S, Yanchar NL. Identification of blunt abdominal injuries in children. J Trauma Acute Care Surg. 2014;76:95-100

15. Paltiel HJ, Barth RA, Bruno C, Chen AE, Deganello A, Harkanyi Z, et al. Contrast-enhanced ultrasound of blunt abdominal trauma in children. Pediatr Radiol. 2021. https://doi.org/10.1007/s00247-020-04869-w.

16. Holmes JF, Mao A, Awasthi S, McGahan JP, Wisner DH, Kuppermann N. Validation of a prediction rule for the identification of children with intra-abdominal injuries after blunt torso trauma. Ann Emerg Med. 2009;54:528-33.

17. Lee JY, Cho DH, Lee JG, Shin H, Lee YJ, Lee SH. A nomogram predicting the need for abdominal and pelvic computed tomography in blunt trauma patients: a retrospective cohort study. Int J Surg. 2017;47:127-34.
18. Zagory JA, Dossa A, Golden J, Jensen AR, Goodhue CJ, Upperman JS, et al. Re-evaluation of liver transaminase cutoff for $C T$ after pediatric blunt abdominal trauma. Pediatr Surg Int. 2017;33:311-6.

19. Abbasi S, Shaker H, Zareiee F, Farsi D, Hafezimoghadam P, Rezai M, et al. Screening performance of ultrasonographic B-lines in detection of lung contusion following blunt trauma; a diagnostic accuracy study. Emerg (Tehran). 2018;6(1):e55.

20. Corwin MT, Sheen L, Kuramoto A, Lamba R, Parthasarathy S, Holmes JF. Utilization of a clinical prediction rule for abdominal-pelvic CT scans in patients with blunt abdominal trauma. Emerg Radiol. 2014;21:571-6.

21. Deunk J, Brink M, Dekker HM, Kool DR, Blickman JG, van Vugt AB, et al. Predictors for the selection of patients for abdominal CT after blunt trauma: a proposal for a diagnostic algorithm. Ann Surg. 2010;251:512-20.

\section{Publisher's Note}

Springer Nature remains neutral with regard to jurisdictional claims in published maps and institutional affiliations.

\section{Submit your manuscript to a SpringerOpen ${ }^{\circ}$ journal and benefit from:}

- Convenient online submission

- Rigorous peer review

- Open access: articles freely available online

- High visibility within the field

- Retaining the copyright to your article

Submit your next manuscript at $\boldsymbol{\nabla}$ springeropen.com 